most likely to develop rises of more than $90 \mu \mathrm{mol} / 1(1.0 \mathrm{mg} /$ $100 \mathrm{ml}$ ), for relatively less damage will produce greater rises of plasma creatinine concentrations when renal function is already impaired. Nevertheless, a 33\% incidence of rises of more than $90 \mu \mathrm{mol} / 1$ in those with high initial plasma creatinine concentrations (over $220 \mu \mathrm{mol} / 1(2.5 \mathrm{mg} / 100 \mathrm{ml})$ ) certainly indicates a common problem. In contrast, only $2 \%$ of patients with less abnormal or normal initial function showed rises of the same order. The authors concluded that the contrast agent was toxic and the renal failure was a real event. Another recent review concluded that little useful was obtained from contrast studies in acute renal failure and that the risk was considerable and far outweighed the benefits, ${ }^{7}$ and similar if less dogmatic recommendations have recently come from the British group at St Bartholomew's Hospital that were previously ${ }^{2} 3$ enthusiastic advocates of contrast radiology.

In contrast recent British reviews that have reached publication suggest that it is diagnostic uncertainty that is dangerous and that any dangers of contrast studies are offset by the merits of knowing what condition a patient has got, or more often what he has not got-obstruction. Part of the explanation for recent changes in opinion in the United States and in relatively well funded London units, working with staff having a specialised interest in renal radiology, is the improvement in non-invasive techniques, such as ultrasound, radionuclide, and computed tomography scanning-but we should remember that facilities for these latter techniques are inadequate or unavailable in many parts of the world outside North America and London. Adoption of the extreme caution now seen in the United States would mean a major change in policy for most British units. Furthermore, uncertainty about obstruction may persist even when the renal tract has clearly been shown to be non-dilated, ${ }^{4}$ and an abnormal nephrogram may be a diagnostic clue in cases of calculus anuria in patients in whom obstruction would be missed with ultrasound or computed tomography.

When contrast studies are considered important, whether for renal or non-renal indications, and especially if the patient has some impairment of renal function, how can any hazards be reduced? The rare cases of severe damage from an allergic vasculitis or a glomerulonephropathy are difficult to predict and therefore to prevent. Acute renal failure from direct toxic effects should be unusual if care is taken about dose. ${ }^{8}$ Special care should be taken with children. Most deteriorations in renal function are probably due directly or indirectly to the massive solute loads induced during these procedures. The contrast acting as a solute causes intracellular dehydration and extracellular fluid expansion, which with the osmolar load causes a large diuresis. ${ }^{9}$ This in itself may well create a renal crisis in a patient who already has just adequate hydration or mild dehydration. This risk may be reduced by replacing fluid losses before the procedure, by avoiding dehydration and "no fluid" regimens, and by giving extra fluids before, during, or after the investigation. Further studies are needed to establish both whether such precautions will reduce or prevent problems and to decide whether fluid replacement should be as water by mouth, intravenous $5 \%$ dextrose, or some other electrolyte containing supplement. The policy of not adding electrolytes to fluids given during the procedure and of removing them from contrast agents is debatable-for the diuresis is a solute diuresis and removes substantial amounts of sodium and other electrolytes. ${ }^{9}$ For the time being, while the results of such investigations are awaited, the priority should be ensuring good hydration, but the choice of the most appropriate fluid to use will have to be a matter for individual judgment-perhaps water by mouth and $0.45 \%$ saline intravenously. No regimen can be recommended as a recipe for all patients. Evaluation of a patient's hydration requires clinical skills at the bedside. Some patients about to $\underset{D}{2}$ undergo contrast radiography will be dehydrated, others will $C$ have heart failure or have overhydration for other reasons. $\widehat{\widehat{O}}$ Only for the majority who will be correctly hydrated can $\overline{\bar{J}}$ anyone design a standard perioperative programme.

Finally, clinicians need to remember that contrast pro- $\infty$ cedures are often expensive, may be uncomfortable for the $\stackrel{0}{\varrho}$ patient, and are not without some risk. More thought and study are needed on how to reduce the risk, but as more $\stackrel{9}{9}$ equipment and staff become available for non-invasive ? investigative techniques there should be less need for angio- $\frac{\bar{\sigma}}{\bar{D}}$ graphic and other more hazardous investigative procedures. $\frac{\vec{\sigma}}{\overrightarrow{0}}$

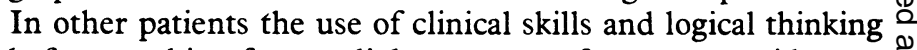

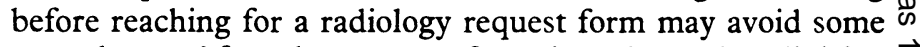
procedures. After the request form is written the clinician $\overrightarrow{0}$ still has a responsibility to take enough care with his patients' $\overrightarrow{\vec{\omega}}$ management before, during, and after the investigations if he $\stackrel{\omega}{\sigma}$ is to keep any risk to a minimum.

University Research Fellow,

MARTIN S KNAPP

Queen's Medical Centre,

Nottingham NG7 2UH

(Formerly Consultant Renal Physician,

Nottingham City Hospital)

1 Schwartz WB, Hurwit A, Ettinger A. Intravenous urography in the $N$

patient with renal insufficiency. $N$ Engl f Med $1963 ; 269: 277-83$.
${ }^{2}$ Fry IK, Cattell WR. The IVP in renal failure. Br $\mathcal{F}$ Hosp Med 1970;3: 67-71.

${ }^{3}$ Fry IK, Cattell WR. The nephrographic pattern during excretion $\vec{\bullet}$ urography. Br Med Bull 1972;28:227-32.

4 Davies P. Urographic appearances in renal failure due to intraluminal ureteric obstruction. $\mathcal{F} R$ Soc Med 1982;75:768-71.

${ }^{5}$ Berman LB. Interstitial nephritis and systemic disorders of the kidney. In: Gonick HC, ed. Current nephrology. Vol 5. New York: J Wiley and Sons, 1982:189-213.

${ }^{6}$ D'Elia JA, Gleason RE, Alday M, et al. Nephrotoxicity from angiographic 岗 contrast material. Am $\mathcal{F}$ Med $1982 ; 72: 719-25$.

${ }^{7}$ Kirchenbaum MA, Nissenson AR. Acute renal failure. In: Gonick HC, ed. $\overrightarrow{\vec{a}}$ Current nephrology. Vol 5. New York: J Wiley and Sons, 1982:241-70. 윽

${ }^{8}$ Anonymous. Radiocontrast-induced renal failure. Lancet 1979;ii:835.

${ }^{9}$ Harris FH, Glassock RJ. Osmotic diuresis after radio-contrast agents. Kidney Int 1983;23:125.

\section{Which inguinal hernia repair?}

Modern surgical repair of inguinal hernia is less than 100 years old. In that time the methods have passed through three $\tilde{N}^{N}$ phases. The original techniques were developed by pioneers $\underset{\mathcal{N}}{\tilde{N}}$ such as Bassini ${ }^{1}$ and Halsted, ${ }^{2}$ who described the suturing ? together of the margins of the defect. There followed a second $\stackrel{\varrho}{\subseteq}$ phase of imaginative solutions to the problem of closing the $\stackrel{\oplus}{\rightarrow}$ defect using flaps, darns, inserted fascia, skin, and tantalum gauze. The methods now in vogue all depend on the drawing 0 together of tissues already present, the elimination of tension, $\stackrel{\mathbb{D}}{\stackrel{D}{\circ}}$ and the use of non-absorbable sutures.

Three techniques are popular. Tension may be eliminated $\underset{2}{2}$ when using the original Bassini technique by making a relaxing incision ${ }^{3}$ which allows the upper edge to be drawn down easily to the inguinal ligañent. The relaxed upper edge is slid down in the Anson and McVay method, ${ }^{4}$ to be sutured $?$ to the ligament of Cooper and the anterior femoral shextin. 
The method of Shouldice ${ }^{5}$ depends on preliminary repair by overlapping of the transversalis fascia forming the posterior wall of the inguinal canal followed by a modified Bassini type of repair.

It should be possible to determine the method that most effectively prevents recurrences, but carefully controlled clinical trials are difficult to construct because of the number of variables. Patients vary in age, sex, obesity, and activity. Hernias are indirect or direct, small or large, recent or long standing, with firm or diffuse margins to the defect. Surgeons vary in experience, meticulousness, enthusiasm for carrying out large numbers of hernia repairs, and desire to follow up their patients for long periods and adjust the technique in response to the results. The most variable aspect of all is operative method: some techniques named for an originator would be disowned by him because the user has neither watched him nor even bothered to read his original description. In addition, none of us can resist adding our own little "improvements."

Methods of reporting the results also vary. Some patients are personally followed up for long periods, others for short periods with indirect assessment of recurrence. Recurrence is usually given as an overall percentage but may be calculated after separating the original hernias into different groups and using statistical corrections. ${ }^{6}$

Nevertheless, certain trends emerge. Pooled series show high recurrence rates, ${ }^{78}$ individual series show low rates, ${ }^{59}$ but recurrences probably are less frequent than formerly. Before the second world war a surgeon was proud to report recurrence rates of around $5 \%^{10}$ and a review of 13 major studies in 1954 showed recurrence rates as high as $15 \% \%^{11}$ At present large series are reported with recurrence rates below $1 \%{ }^{5} 91213$ We should remember, however, that the surgeons who report most of the results do not perform most of the hernia repairs. The writers of papers are enthusiasts, committed to promulgating a method and striving to achieve better results than others. Most of the herniorrhaphies in Britain and elsewhere ${ }^{6}$ are performed by surgeons in training. Sir Cecil Wakeley made a statement on cost effectiveness before that term became fashionable when he stated ${ }^{10}$ in 1940 : "A surgeon can do more for the community by operating on hernia cases and seeing that his recurrence-rate is low than he can by operating on cases of malignant disease."

One common argument is that the type of repair should be tailored to the type of hernia, ${ }^{6}$ so that difficult, diffuse hernias may require extra precautions to facilitate closure of the defect. $^{1415}$ At the Shouldice Clinic in Toronto a single method is used, almost unvaried, for all types of hernia, and Glassow $^{5}$ from there has now reviewed his enormous experience and outstanding results in a Hunterian lecture at the Royal College of Surgeons of England.

In my experience outstanding and thoughtful surgeons who devise a new technique attribute their success to the method. They are too modest. Their colleagues know that it is not the particular method that brings success but the enthusiasm for perfection and the painstaking skill with which it is accomplished. If I develop a hernia I shall not worry about the method of repair but about who is carrying it out.

R M KIRK

Consultant Surgeon,

Royal Free Hospital,

London NW3 2QG

${ }^{1}$ Bassini E. Ueber die Behandlung des Leistenbruches. Langenbecks Archiv für Klinische Chirurgie 1890;40:429-76.
${ }^{2}$ Halsted WS. The radical cure of inguinal hernia in the male. Bulletin of the fohns Hopkins Hospital 1893;iv:17-24.

3 Tanner NC. A "slide" operation for inguinal and femoral hernia. Brf Surg $1942 ; 29: 285-9$.

${ }^{4} \mathrm{McVay}$ CB, Anson BJ. Inguinal and femoral hernioplasty. Surg Gynecol Obstet $1949 ; 88: 473-85$.

5 Glassow F. Short-stay surgery (Shouldice technique) for repair of inguinal hernia. Ann R Coll Surg Engl 1976;58:133-9.

${ }^{6}$ Asmussen T, Jensen FU. A follow-up study on recurrence after inguinal hernia repair. Surg Gynecol Obstet 1983;156:198-200.

${ }^{7}$ Shuttleworth KE, Davies WH. Treatment of inguinal herniae. Lancet $1960 ; \mathrm{i}: 126-7$.

${ }^{9}$ Marsden AJ. Inguinal hernia. A three-year review of two thousand cases. Br F Surg 1962;49:384-94.

${ }^{9}$ Rutledge RH. Cooper's.ligament repair for adult groin hernias. Surgery 1980;87:601-10.

10 Wakeley CPG. Treatment of certain types of external herniae. Lancet $1940 ; i: 822-6$.

11 Doran FSA. Three methods of repairing the deep abdominal ring in men with primary indirect inguinal hernia. Br ₹ Surg 1962;49:642-9.

${ }^{12}$ Lichtenstein IL, Shore JM. Exploding the myths of hernia repair. $A m \mathcal{F}$ Surg 1976;132:307-15.

${ }^{13}$ Devlin HB, Russell IT, Muller D, Sahay AK, Tiwari PN. Short-stay surgery for inguinal hernia. Clinical outcome of the Shouldice operation. Lancet 1977 ; : $847-9$.

14 Hagan WH, Rhoads JE. Inguinal and femoral hernias. A follow-up study. Surg Gynecol Obstet 1953;96:226-32.

15 Kirk RM. Intra-abdominal replacement of the testis as an aid to the repair of difficult and recurrent inguinal hernias. Br F Surg 1974;61:538.

\section{Causes of insulin dependent diabetes}

Ancient Indian physicians believed that diabetes was a heterogenous disease caused by genetic and environmental factors. The evidence is that they were correct, and we now recognise two major types of diabetes which are genetically distinct-insulin dependent diabetes and non-insulin dependent diabetes. ${ }^{1}$

Genetic influences are powerful in insulin dependent diabetes, especially through genes in the HLA region (HLA-B8, B15, DR3, and DR4). But juvenile onset insulin dependent diabetes is at least partly determined by non-genetic factors. Studies of identical twins have shown that half of those with insulin dependent diabetes have an unaffected cotwin; and as identical twins share the same genes such differences must be due to environmental agents. ${ }^{2}$ Even insulin dependent twins with an unaffected cotwin, however, are genetically susceptible to the disease, so it is unlikely that environmental agents are entirely responsible for insulin dependent diabetes. ${ }^{3}$

If insulin dependent diabetes is caused by both genetic and environmental factors and they interact then they probably do so through the immune system. Unlike non-insulin dependent diabetes, the immune system has been implicated in the pathogenesis of insulin dependent diabetes: the HLA region is the same genetic region which controls the immune response in mice, and the disease is associated with autoimmune diseases such as hypothyroidism. ${ }^{1}{ }^{4}$ In addition, recently diagnosed insulin dependent diabetics have mononuclear inflammatory cells permeating and surrounding their islet cells and islet cell antibodies. ${ }^{5}$ This insulitis might be produced either by destruction of islet cells or by an autoimmune reaction; both could be caused by an environmental agent acting in a genetically susceptible host.

What is the environmental agent responsible for insulin dependent diabetes? Attention has focused on viruses and toxins. "Wild" viruses exist which have a specific $\beta$ cell 